\title{
LOW HOST SPECIFICITY OF ARBUSCULAR MYCORRHIZAL FUNGI ASSOCIATED WITH DOMINANT STEPPE PLANTS IN INNER MONGOLIA
}

\author{
MunEeR, M. A. ${ }^{1 \#}-$ WANG, M. ${ }^{2 \#}-$ Jing, Z. ${ }^{1}-$ ZHOU, X. ${ }^{1}-$ WANG, P. ${ }^{1}-$ LI, L $.{ }^{3}-$ JI, B. ${ }^{1 *}$ \\ ${ }^{1}$ College of Grassland Science, Beijing Forestry University, Beijing 100083, China \\ ${ }^{2}$ Key Laboratory for Biodiversity Science and Ecological Engineering, Ministry of Education, \\ Fudan University, Shanghai, China \\ ${ }^{3}$ College of Biological Sciences and Technology, Beijing Forestry University, Beijing 100083, \\ China
}

${ }^{\#}$ These authors have contributed equally to this work.

*Corresponding author

e-mail: baomingji@bjfu.edu.cn

(Received $27^{\text {th }}$ Apr 2019; accepted $2^{\text {nd }}$ Jul 2019)

\begin{abstract}
Arbuscular mycorrhizal fungi (AMF) play potentially essential roles in maintaining the diversity and functioning of plant communities in Eurasian steppe representing one of the most important terrestrial ecosystems. However, it remains unclear about the symbiotic relationship between AM fungal communities and the dominant grass species in the steppe ecosystem. We thus examined the species diversity and community composition of AM fungi colonizing three dominant plant species (Leymus chinensis, Stipa grandis and Cleistogenes squarrosa), using field sampling and molecular analyses, in Xilinguole steppe, Inner Mongolia. Our results showed all three plants were well colonized by AM fungi, and 51 operational taxonomic units (OTUs) belonging to six genera with members of Glomus dominating in the roots of all the three plants species. By comparison, we found that $L$. chinensis had the most diverse AM fungi within the roots. OTU richness of AM fungi was higher in the roots of $S$. grandis than in the roots of $C$. squarrosa and $L$. chinensis. However, the community composition of AM fungi in three host plant species showed no significant difference. Based on these findings, we concluded that the dominant plant species held diverse AM fungal taxa in their roots, while the host preference did not significantly drive the differences in AM fungal community composition within their roots and resulted in low host specificity. Findings of this study would broaden the concept of host specificity and its implications on plant succession in the largest grassland ecosystem of China.
\end{abstract}

Keywords: arbuscular mycorrhizal fungi, diversity, community composition, host specificity, symbiosis

\section{Introduction}

Arbuscular mycorrhizal (AM) symbiosis formed between higher plant roots and the fungi belonging to the phylum Glomeromycota is one of the most common mutualistic associations in terrestrial ecosystems (Desai et al., 2016; Stürmer, 2012). In grasslands, the vast majority of plant species are AMF hosts (Bonfante and Genre, 2010; Eom et al., 2000; Harrier, 2001). In these symbiotic associations, plants provide carbon to the fungi to complete their life cycle (Zhang et al., 2016b). In return, AMF benefits their hosts in various ways including enhanced nutrient acquisition and improved protection against biotic and abiotic stresses (Latef et al., 2016; Huang et al., 2017; Chen et al., 2017). Therefore, AM symbionts could play potentially 
important roles in plant growth, community diversity and ecosystem stability (Torrecillas et al., 2012).

The host plant strongly influences the AMF diversity and community composition inside the roots (Pivato et al., 2007; López-García et al., 2014; Zheng et al., 2016). However, owing to the wide range of preference for host plants (Krüger et al., 2012), the AMF normally show low host specificity (Lee et al., 2013), and most of the previous studies found that AMF had no host specificity (Clapp et al., 1995; Santos et al., 2006; Smith and Read, 2008). For example, Su et al. (2011) studied the AMF community composition in five plant species of Inner Mongolia and found 18 AMF species belonging to five genera and concluded that most of the AMF had no host specificity, but few species showed a certain degree of the host preference. However, some findings showed that AMF community composition is host-dependent (Lugo and Cabello, 2002; del Mar Alguacil et al., 2018). Bentivenga and Hetric (1992) found host plant had a significant effect on AM fungal sporulation in tallgrass prairie grasses. Li et al. (2010) explored three plant species of hot and arid ecosystem of southwest China and found different AM fungal community composition. Several studies have documented that selectivity between AMF and host plants may be the cause of presence or absence of host specificity (Bever, 2002; Helgason et al., 2002; Zhang et al., 2010). Moreover, Yang et al. (2012) hypothesized that discerning pressure from host plant at different levels (functional groups and taxonomic order) may be a driver for the distribution of AMF. However, the detailed explanation still needs several studies. The previous suppositions are mainly based on morphological investigations and a little molecular work is involved. Therefore, considering the contrasting opinions regarding AMF host specificity and insufficient investigations, further studies are needed to deepen the understanding about the role of AMF in typical steppe. This would broaden the concept of host specificity and its implications on plant succession in the largest grassland ecosystem of China because the low host specificity favours underground communication and nutrient transfer pathways via mycorrhizal networks.

The typical steppe in Inner Mongolia covers more than $20 \%$ of total grassland area in China (Xu et al., 2014), and AMF holds a significant value in the success of plant species in the steppe. In this study, we analyzed and compared the diversity and community composition of AMF colonizing the roots of three dominant perennial plant species; Leymus chinensis (L. chinensis), Stipa grandis (S. grandis), and Cleistogenes squarrosa (C. squarrosa). These three plant species are considered longlived dominant grass species of the typical steppe, Xilinguole (Vandenkoornhuyse et al., 2003). The sheepgrass (L. chinensis) is a perennial forage plant and of great significance for grassland productivity and ecosystem (He et al., 2017). While, $S$. grandis is known as needlegrass also has significant nutritional value for the cattle and sheep in this region of Inner Mongolia (Su et al., 2010). The Cleistogene squarrosa is the most abundant $\mathrm{C}_{4}$ perennial bunchgrass species of this region and the importance of Cleistogene has been recognized for the development of sustainable grassland system (Liang et al., 2002). Concerning the ecological and economic importance of these three plant species, our goal was to identify the differences in diversity and community composition of AMF in three plant species belonging to the same family (Poaceae) to determine the host specificity. These findings can do a great deal towards a comprehensive understanding of AM fungi associations with roots of perennial plant species and host specificity. 


\section{Materials and methods}

\section{Study site}

The study was carried out in the Inner Mongolia Grassland Ecosystem Research Station $\left(43^{\circ} 38^{\prime} 55.9^{\prime \prime} \mathrm{N}, 116^{\circ} 09^{\prime} 06.3^{\prime \prime} \mathrm{E}\right)$, Inner Mongolia Autonomous of China (Fig. 1). This grassland system has semiarid climatic conditions with a short plant growing period ranging from May to September. The average annual precipitation is $343 \mathrm{~mm}$, and the mean annual temperature is $0.3{ }^{\circ} \mathrm{C}$ with average monthly temperature ranging from $-21.6{ }^{\circ} \mathrm{C}$ (January) to $19.0^{\circ} \mathrm{C}$ (July). The main soil type in this site is chestnut soil with relatively homogenous physical and chemical properties (Li et al., 2015; Ren et al., 2016).
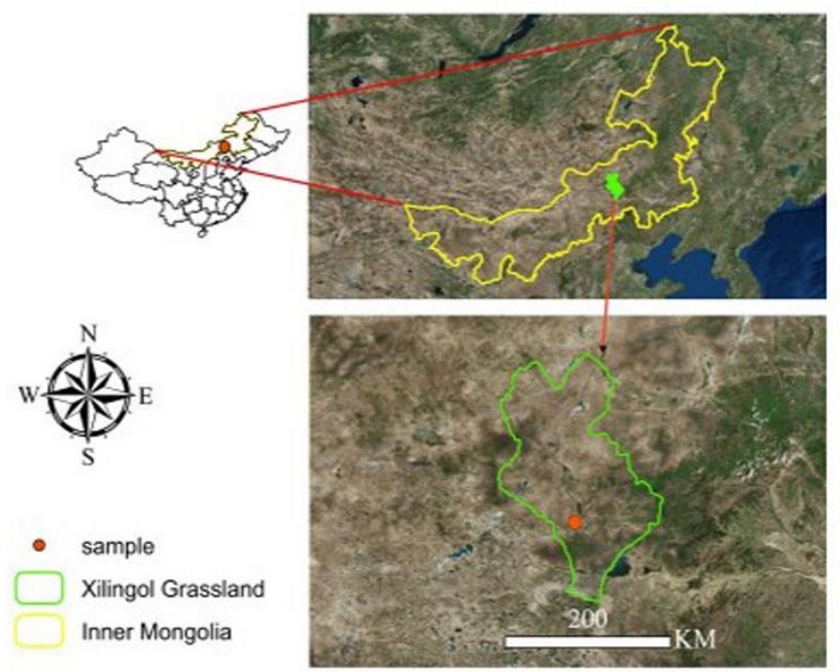

Figure 1. The geographic location of the sampling site. The green line is the boundary of grassland and red dot is the location of sample plot. The map was created with ArcGIS 10.2

\section{Field sampling}

The sampling was performed on June 24,2014 , and we randomly selected seven sampling points with a distance of $100 \mathrm{~m}$ from each other in a $1 \times 1 \mathrm{~km}$ area as replicates. So, we collected 21 total plant samples and seven samples per species. To diminish the influence of soil type and geographic factors for each point, we selected closely adjacent $L$. chinensis, $S$. grandis, and $C$. squarrosa species for each sampling point. Corresponding, we obtained the roots and the rhizosphere soil of each plant using the soil drill. All the samples were preserved in zip lock bags and stored at $4{ }^{\circ} \mathrm{C}$.

\section{AMF structure and colonization}

AMF colonization or root length colonization is an indicator of fungal growth within plant roots. In this study, the roots of the collected plants were washed carefully with tap water and cut into segments of $1 \mathrm{~cm}$ length. For each sample, approximately 100 root segments were randomly chosen and cleared in $10 \% \mathrm{KOH}$ at $90{ }^{\circ} \mathrm{C}$ and stained with $0.05 \%$ Trypan blue, and then examined the percentage of AMF colonization using the magnified intersection method at 200× magnification (Nikon-E100) (Mcgonigle et al., 1990). 


\section{DNA extraction and sequencing}

In our study, the AM fungi within the roots of L. chinensis, S. grandis, and $C$. squarrosa was identified through PCR amplified 18S-rRNA gene fragments with AMFspecific primers, as partial sequences of small subunit (SSU) genes appeared to be more informative than ITS genes for AM fungi (Redecker et al., 2006). For each sample, the total DNA was extracted from 80 randomly obtained fine roots using MoBio Power Soil ${ }^{\circledR}$ DNA Isolation kits (QIAGEN, Valencia, CA, USA). 18S rRNA gene was amplified using a nested PCR protocol. Based on the previous study (Krüger et al., 2009), the chosen primers were AML1/AML2 because they have better coverage and specificity than NS31/AM1, which have been extensively used in recent years (Helgason et al., 1999; Simon et al., 1992). A 10-fold dilution of the DNA was first amplified using the general eukaryotic primers NS1/NS4 (White et al., 1990). In the second phase of nested PCR, the product was amplified using AML1/AML2, and the PCR product was visualized on $1 \%$ agarose gel. The expected 800 bp bands were cut out and purified using an AxyPrep DNA Gel Extraction Kit (Axygen, Union City, CA, USA). The purified product was sequenced using the Sanger platform to confirm the presence of AM fungi before proceeding further. Purified DNA was cloned into the pGEM-T Easy vector (Promega, Madison, WI, USA) and then transformed into E. coli DH-5 $\alpha$ (Tiangen, Beijing, China). The resulting DNA sequences were aggregated using BioEdit to perform the subsequent analysis.

\section{Sequence analysis}

We compared our clone DNA sequences with the GenBank database on the NCBI website (http://www.ncbi.nlm.nih.gov/). The closest match was selected to identify the sequences, and only those recognized as Glomeromycota were included for further taxonomic analysis.

All the selected AM fungal sequences were gathered from the previous steps, then we conducted standard operational taxonomic units (OTUs) analysis using the Mothur software (Schloss et al., 2009). The sequences with not less than 97\% matched, were grouped into OTU (Helgason et al., 1998). After finishing clustering, we selected one sequence in each OTU as the representative sequence and aligned them together with their closest matched identified AM fungal sequences from the NCBI database; then Mega 6.06 program (Kumar et al., 2007) was utilized to align the sequences. Furthermore, in Mega, Kimura2-parameter model was computed to perform neighborjoining phylogenetic analysis with 1000 bootstrap replicates to calculate the support value of the tree with Mortierella polycephala (ID: X89436) and Endogone pisiformis (ID: X58724) as outgroups to root the tree (Tamura et al., 2007; Öpik et al., 2003). To further quantify and compare the fungal community diversity, the Shannon-Wiener index was computed with vegan package (Oksanen et al., 2007) in R (Team, 2013) based on the identified OTUs. The Shannon diversity index was calculated according to the following equation:

$$
\mathrm{D}=\sum_{i=1}^{s} p_{i} \times \ln p_{i}
$$

where $\mathrm{S}$ is the total number of species in the sample and $p_{i}$ is the relative abundance of certain AM fungus species of the sample (Shannon and Weaver, 1949). 


\section{Nucleotide sequence accession numbers}

A total of 51 representative sequences of the clones detected were submitted to NCBI (National Center for Biotechnology Information) GenBank (http://www.ncbi.nlm.nih.gov) with the accession number LS997508-LS997558.

\section{Statistical analysis}

The SPSS statistical software was used to compare the AMF colonization rate, species richness, and Shannon diversity indexes among the three species. The data were analyzed using one-way Analysis of Variance method (ANOVA) and significant differences between the different plant species in ANOVA were compared based on Tukey's HSD post-hoc test at $P \leq 0.05$. To gain further insight into the potential relationship between AM fungal communities and their host plant species, NMDS (nonmetric multidimensional scaling) was conducted using PAST (Paleontological Statistics) version 3.21.

\section{Results}

\section{AMF colonization}

The results showed that all the plant species were well colonized by AMF. S. grandis showed an average of $92 \%$ colonization, whereas $C$. squarrosa and $L$. chinensis showed average colonization rates of $87 \%$ and $90 \%$, respectively (Fig. 2). One-way analysis of variance (ANOVA) indicated that there were no significant differences as shown by Tukey's HSD test $(F=(2,18)=0.054)$ in the AMF colonization among the three dominant species.

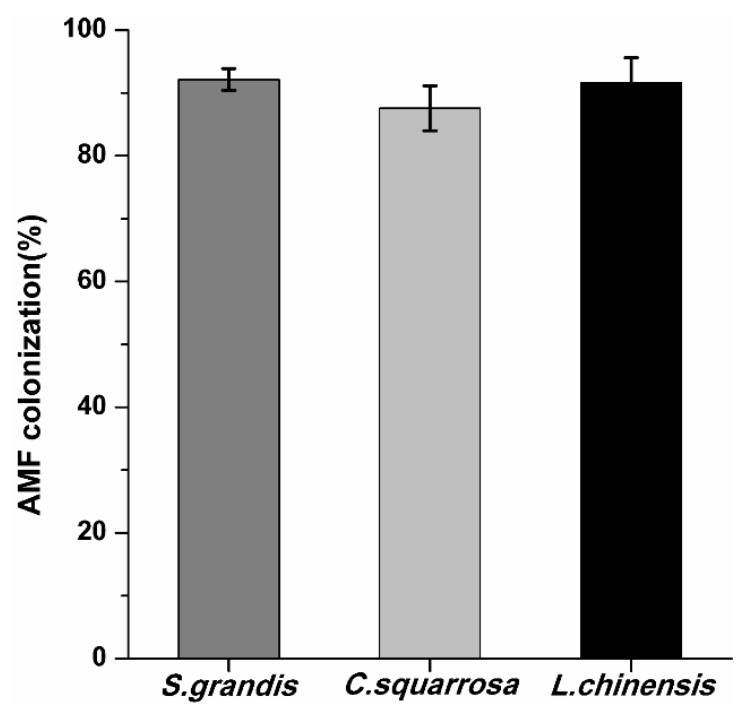

Figure 2. AMF colonization. AM fungal colonization (\%) observed in three plant species. Data are means $\pm S E$

\section{Identification and phylogenetic analysis of AM fungi}

A total of 750 clones were sequenced, and among them, 587 non-chimeric sequences were identified as AMF and clustered into 51 OTUs at $97 \%$ sequence similarity. These 
phylotypes or sequences types classified into six genera including Rhizophagus, Glomus, Diversispora, Claroideoglomus, Paraglomus, and Ambispora (Fig. 3). Of all these AM fungal phylotypes, 19 belonged to Rhizophagus (Rhizophagus 01-19), 24 to Glomus (Glomus 01-24), one from each Diversispora (Diversispora 01) and Claroideoglomus (Claroideoglomus 01), four from Paraglomus (Paraglomus 01-04), and Ambispora (Ambispora 01-02) group contains two phylotypes.

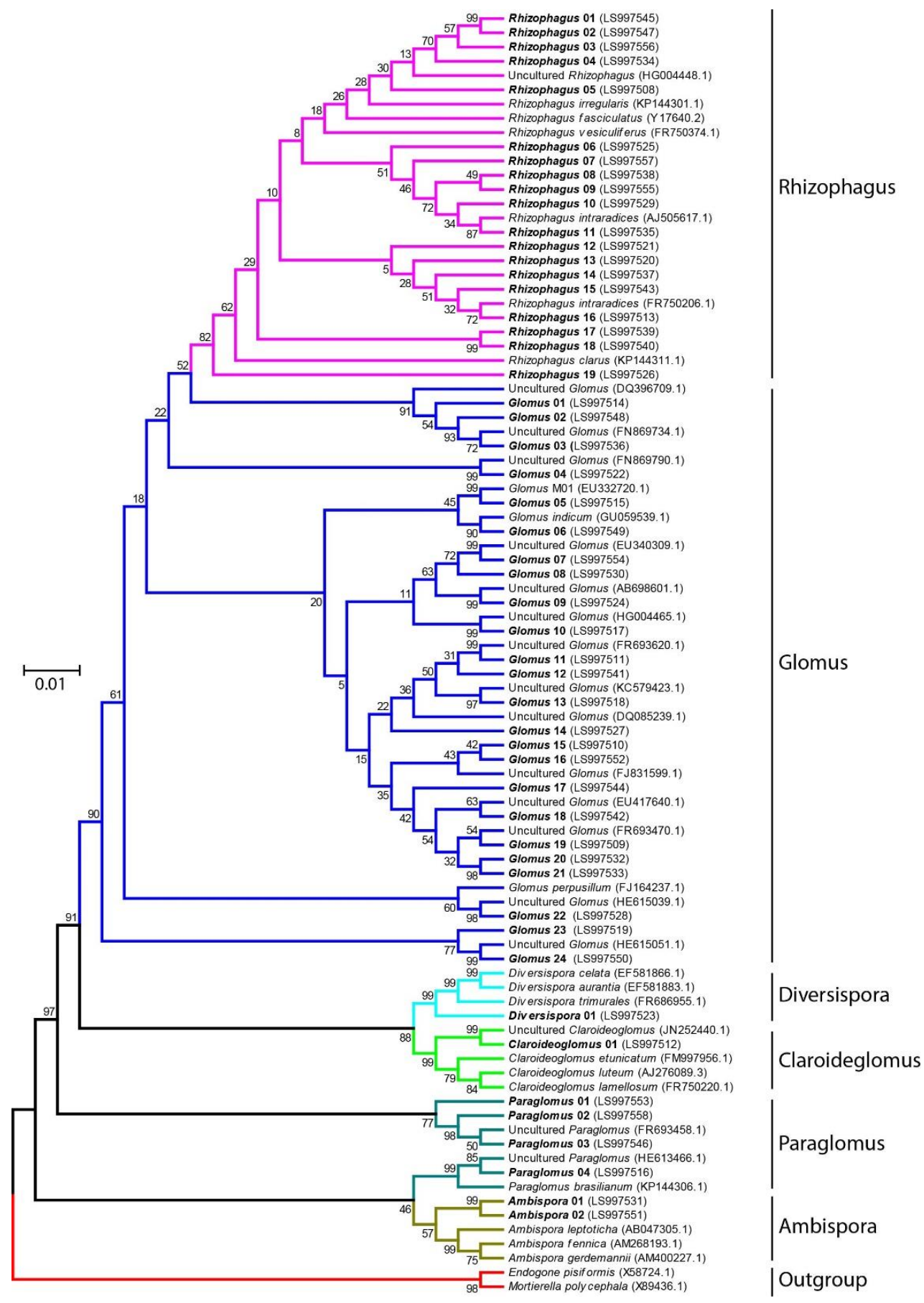

Figure 3. Phylogenetic tree. The neighbor-joining phylogenetic tree was constructed based on $18 S$ rDNA sequences of the 51 OTUs (bold), and the reference sequences were downloaded from NCBI (their corresponding numbers are shown in the parentheses). The bootstrap values by 1000 replications were calculated. The scale bar represents the sequence divergence at $1 \%$ 
In terms of OTUs, Rhizophagus-05 and Glomus-15 were the most abundant in all three species, with a relative abundance of $27 \%$ and $11 \%$ respectively, whereas Glomus19 was found only in $S$. grandis and C. squarrosa and had a relative abundance of $13 \%$ (Table 1).

Table 1. Number of clones detected for each AM fungi phylotype and relative richness. The most closely related sequences with their accession number from the http://www.ncbi.nlm.nih.gov are given

\begin{tabular}{|c|c|c|c|c|c|}
\hline OTUs identified & $S G$ & $C S$ & $L C$ & Accession & Identity (\%) \\
\hline Rhizophagus 01 (LS997545) & 0 & 0 & 1 & HG004448.1 & 0.99 \\
\hline Rhizophagus 02 (LS997547) & 0 & 0 & 1 & FR693470.1 & 0.99 \\
\hline Rhizophagus 03 (LS997556) & 0 & 1 & 0 & FJ831599.1 & 0.99 \\
\hline Rhizophagus 04 (LS997534) & 1 & 0 & 1 & FR693620.1 & 0.99 \\
\hline Rhizophagus 05 (LS997508) & 40 & 54 & 62 & JN252440.1 & 0.99 \\
\hline Rhizophagus 06 (LS997525) & 5 & 0 & 0 & FR750206.1 & 0.99 \\
\hline Rhizophagus 07 (LS997557) & 1 & 0 & 0 & DQ396709.1 & 0.99 \\
\hline Rhizophagus 08 (LS997538) & 2 & 0 & 0 & EU332720.1 & 0.99 \\
\hline Rhizophagus 09 (LS997555) & 0 & 0 & 1 & HE613466.1 & 0.99 \\
\hline Rhizophagus 10 (LS997529) & 0 & 2 & 1 & HG004465.1 & 0.99 \\
\hline Rhizophagus 11 (LS997535) & 0 & 2 & 0 & KC579423.1 & 0.99 \\
\hline Rhizophagus 12 (LS997521) & 4 & 0 & 7 & EU340309.1 & 0.96 \\
\hline Rhizophagus 13 (LS997520) & 10 & 0 & 3 & FR750206.1 & 0.99 \\
\hline Rhizophagus 14 (LS997537) & 1 & 1 & 0 & FR750206.1 & 0.99 \\
\hline Rhizophagus 15 (LS997543) & 0 & 1 & 0 & FN869790.1 & 0.99 \\
\hline Rhizophagus 16 (LS997513) & 5 & 15 & 1 & FR686955.1 & 0.95 \\
\hline Rhizophagus 17 (LS997539) & 0 & 1 & 0 & AB698601.1 & 0.99 \\
\hline Rhizophagus 18 (LS997540) & 1 & 0 & 0 & FR750374.1 & 0.98 \\
\hline Rhizophagus 19 (LS997526) & 2 & 1 & 1 & Y17640.2 & 0.98 \\
\hline Glomus 01 (LS997514) & 2 & 17 & 0 & DQ085239.1 & 0.98 \\
\hline Glomus 02 (LS997548) & 1 & 0 & 0 & HE615039.1 & 0.98 \\
\hline Glomus 03 (LS997536) & 2 & 0 & 0 & Y17640.2 & 0.97 \\
\hline Glomus 04 (LS997522) & 1 & 0 & 10 & EU340309.1 & 0.99 \\
\hline Glomus 05 (LS997515) & 12 & 6 & 0 & AM268193.1 & 0.88 \\
\hline Glomus 06 (LS997549) & 1 & 0 & 0 & FR693470.1 & 0.96 \\
\hline Glomus 07 (LS997554) & 0 & 0 & 1 & FR693470.1 & 0.98 \\
\hline Glomus 08 (LS997530) & 3 & 0 & 0 & HG004448.1 & 0.98 \\
\hline Glomus 09 (LS997524) & 1 & 0 & 6 & AJ505617.1 & 0.97 \\
\hline Glomus 10 (LS997517) & 3 & 0 & 14 & FN869790.1 & 0.98 \\
\hline Glomus 11 (LS997511) & 3 & 23 & 5 & FR750206.1 & 0.96 \\
\hline Glomus 12 (LS997541) & 0 & 1 & 0 & Y17640.2 & 0.97 \\
\hline Glomus 13 (LS997518) & 7 & 3 & 6 & Y17640.2 & 0.97 \\
\hline Glomus 14 (LS997527) & 2 & 0 & 1 & Y17640.2 & 0.87 \\
\hline Glomus 15 (LS997510) & 20 & 23 & 22 & FR693620.1 & 0.97 \\
\hline Glomus 16 (LS997552) & 0 & 1 & 0 & EU417640.1 & 0.98 \\
\hline Glomus 17 (LS997544) & 1 & 0 & 0 & FR750206.1 & 0.96 \\
\hline Glomus 18 (LS997542) & 0 & 1 & 0 & FR693470.1 & 0.97 \\
\hline Glomus 19 (LS997509) & 27 & 48 & 0 & HG004448.1 & 0.97 \\
\hline
\end{tabular}




\begin{tabular}{c|c|c|c|c|c} 
Glomus 20 (LS997532) & 0 & 2 & 0 & FR693458.1 & 0.97 \\
Glomus 21 (LS997533) & 2 & 0 & 0 & HG004448.1 & 0.96 \\
Glomus 22 (LS997528) & 3 & 0 & 0 & DQ396709.1 & 0.95 \\
Glomus 23(LS997519) & 1 & 0 & 13 & GU059539.1 & 0.97 \\
Glomus 24(LS997550) & 0 & 0 & 1 & HE615051.1 & 0.97 \\
Diversispora 01 (LS997523) & 0 & 0 & 8 & AM268193.1 & 0.87 \\
Claroideoglomus 01 (LS997512) & 0 & 0 & 30 & FJ831599.1 & 0.98 \\
Paraglomus 01 (LS997553) & 1 & 0 & 0 & FR693458.1 & 0.96 \\
Paraglomus 02 (LS997558) & 0 & 0 & 1 & EU340309.1 & 0.98 \\
Paraglomus 03 (LS997546) & 1 & 0 & 0 & Y17640.2 & 0.97 \\
Paraglomus 04 (LS997516) & 0 & 17 & 0 & HG004448.1 & 0.96 \\
Ambispora 01 (LS997531) & 1 & 0 & 2 & AJ505617.1 & 0.97 \\
Ambispora 02 (LS997551) & 0 & 0 & 1 & FR693458.1 & 0.96 \\
Total clones & $\mathbf{1 6 7}$ & $\mathbf{2 2 0}$ & $\mathbf{2 0 0}$ & & \\
Total richness & $\mathbf{3 2}$ & $\mathbf{2 0}$ & $\mathbf{2 5}$ & & \\
\hline
\end{tabular}

\section{AMF diversity inside roots}

The most dominant genera were Glomus and Rhizophagus, accounting for 50\% and $39 \%$ of the total clones, respectively, whereas, the Ambispora and Diversispora were the least frequent genera, making up only $0.6 \%$ and $1 \%$ of the total clones, respectively (Fig. 4). At the genus level, all six AM fungal genera were found in L. chinensis whereas only four and three genera were found in $S$. grandis and C. squarrosa, respectively (Fig. 4).

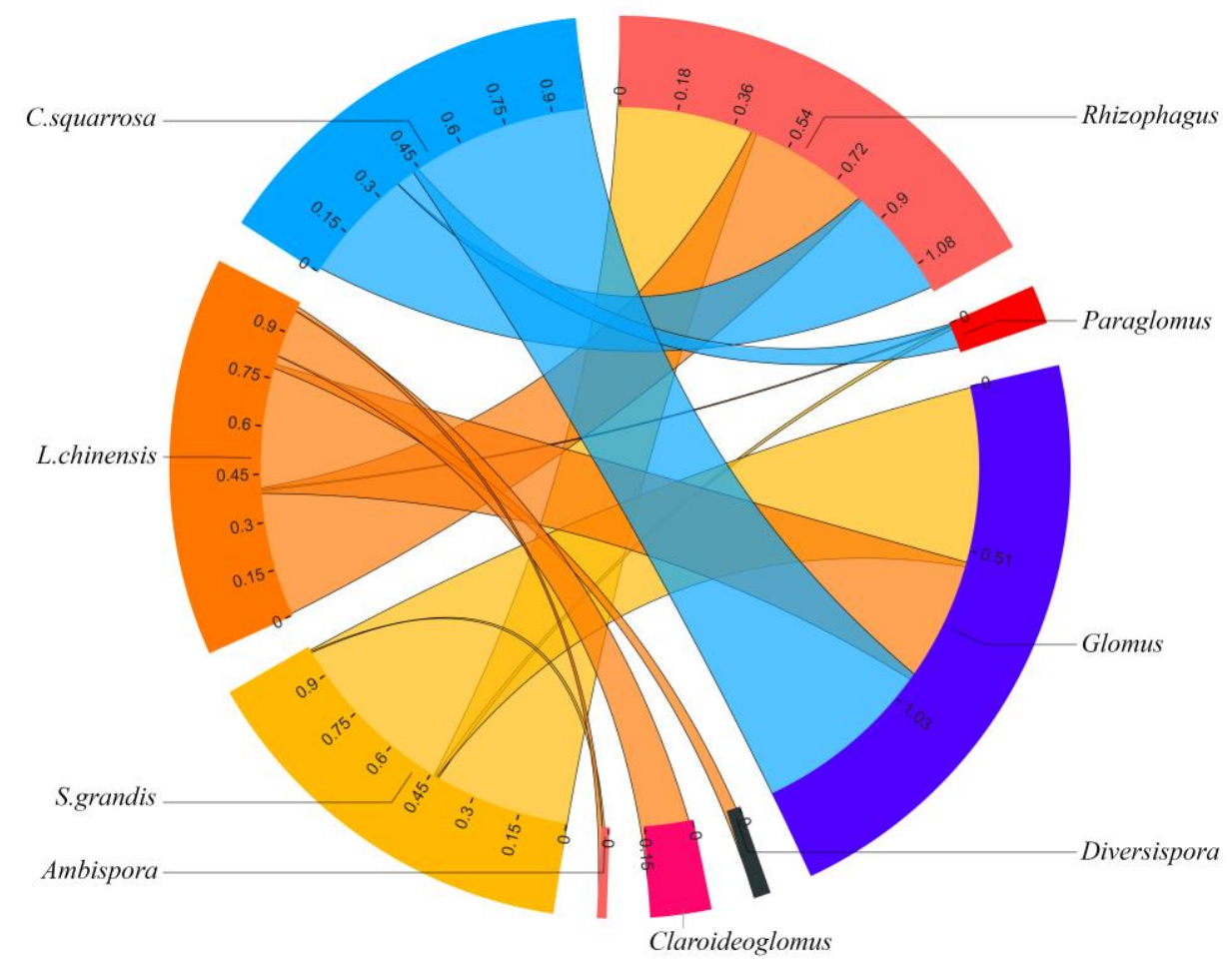

Figure 4. Chord diagram showing the relative abundance of AMF. The relative abundance of $A M F$ genera detected in the roots of the three plant species 
Likewise, the detected OTUs (identified genus) were not evenly distributed among the three plant species. Among the 587 sequence types classified as AM fungi, 167 were from S. grandis, 220 were from C. squarrosa, and 200 were from L. chinensis; however, regarding the OTUs identified data (Table 1), S. grandis appeared to possess the most AMF phylotypes, i.e., 32, whereas, C. squarrosa and L. chinensis possessed 20 and 25 AMF phylotypes, respectively.

Concerning species richness, $S$. grandis also showed the higher richness of the AMF OTUs, followed by C. squarrosa and L. chinensis (Fig. 5). Analysis of variance showed that there were statistically significant differences found in species richness $(p<0.05)$. Therefore, we concluded that $S$. grandis had significantly more diversified AM fungal phylotypes than L. Chinensis and C. squarrosa. Notably, some OTUs were observed for limited hosts. Rhizophagus 06, 07, 08, and 18, Glomus 02, 03, 06, 08, 17, 21, and 22, Paraglomus 01 and 03 were found in S. grandis, Rhizophagus 03, 11, 15, and 17, Glomus 12, 16, 18, 20, and Paraglomus 04 were observed in C. squarrosa, and in $L$. chinensis, Rhizophagus 01, 02, 09, Glomus 07, 24, Diversispora 01, Claroideoglomus 01, Paraglomus 02, and Ambispora 02 were found (Table 1).

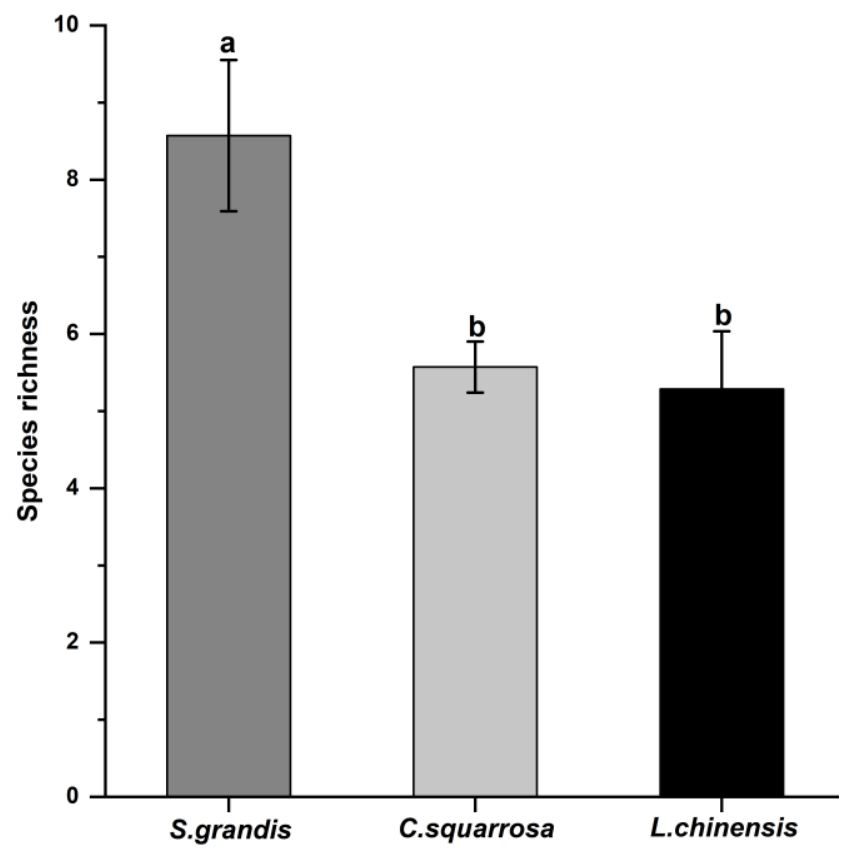

Figure 5. AMF richness. AMF richness in three different plant species. The analysis of variance revealed that $S$. grandis deviated significantly from the other two plant species and showed more species richness. Data are means \pm SE. Identical letters denote non-significant differences, whereas different letters indicate significant differences, as shown by Tukey's HSD test at $P<0.05$

Furthermore, the Shannon-Wiener index used to indicate species diversity in a community. As our results showed, S. grandis, C. squarrosa and L. chinensis exhibited an average value of Shannon diversity index 1.62, 1.30, and 1.08 respectively, and nonsignificant differences were found $(p=0.17)$ (Fig. 6).

The number of OTUs specific to their host plant was 13 for $S$. grandis and 9 for both C. squarrosa and L. chinensis (Fig. 7). The OTUs data set thus demonstrated the 
uniqueness of AMF-plant combinations of dominant plant species found in Xilinguole steppe regions.

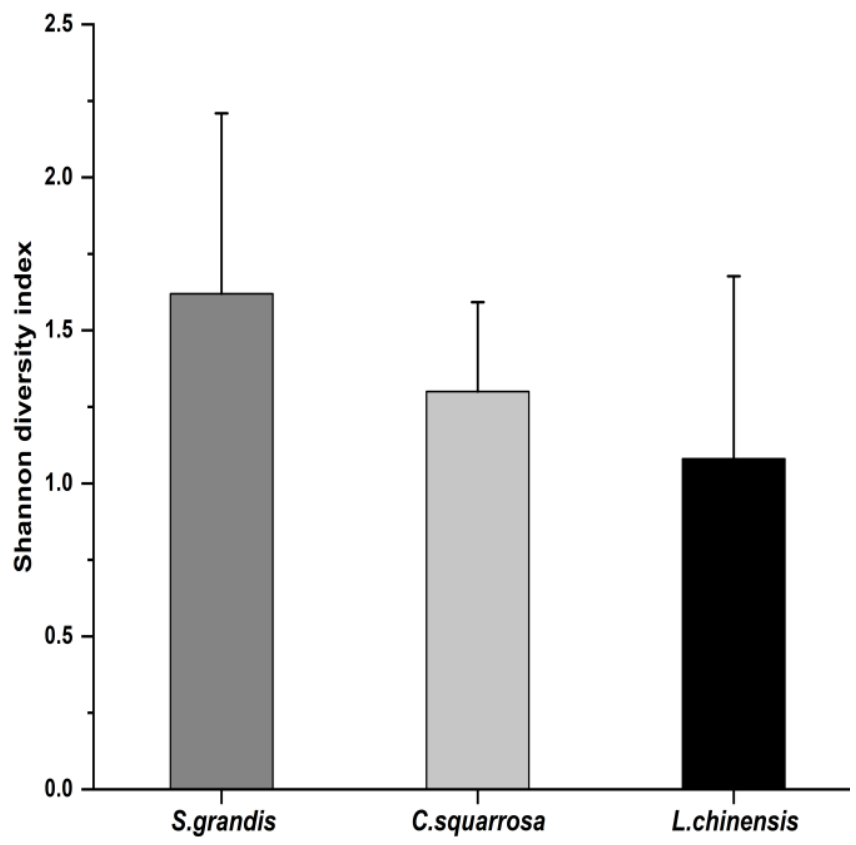

Figure 6. Shannon-Wiener index. The Shannon's diversity index (mean $\pm S E)$, and the analysis of variance revealed a non-significant difference in S. grandis, C. squarrosa, and L. chinensis

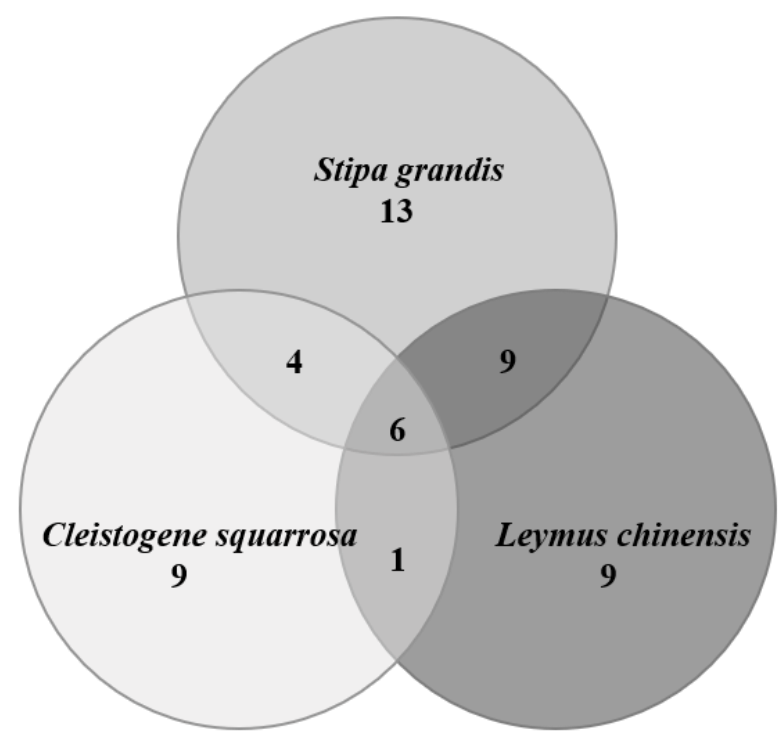

Figure 7. Venn diagram showing the number of shared and unique OTUs among the host plants

Moreover, the NMDS analysis indicated that the AMF community components living with one plant species did not tightly group according to their host plant species (Fig. 8). It implies that at both the genus and OTU levels, AMF showed a host preference character to a certain extent; however, the host plant species may not be solely the determinant for shaping the overall AM fungal community within roots. 


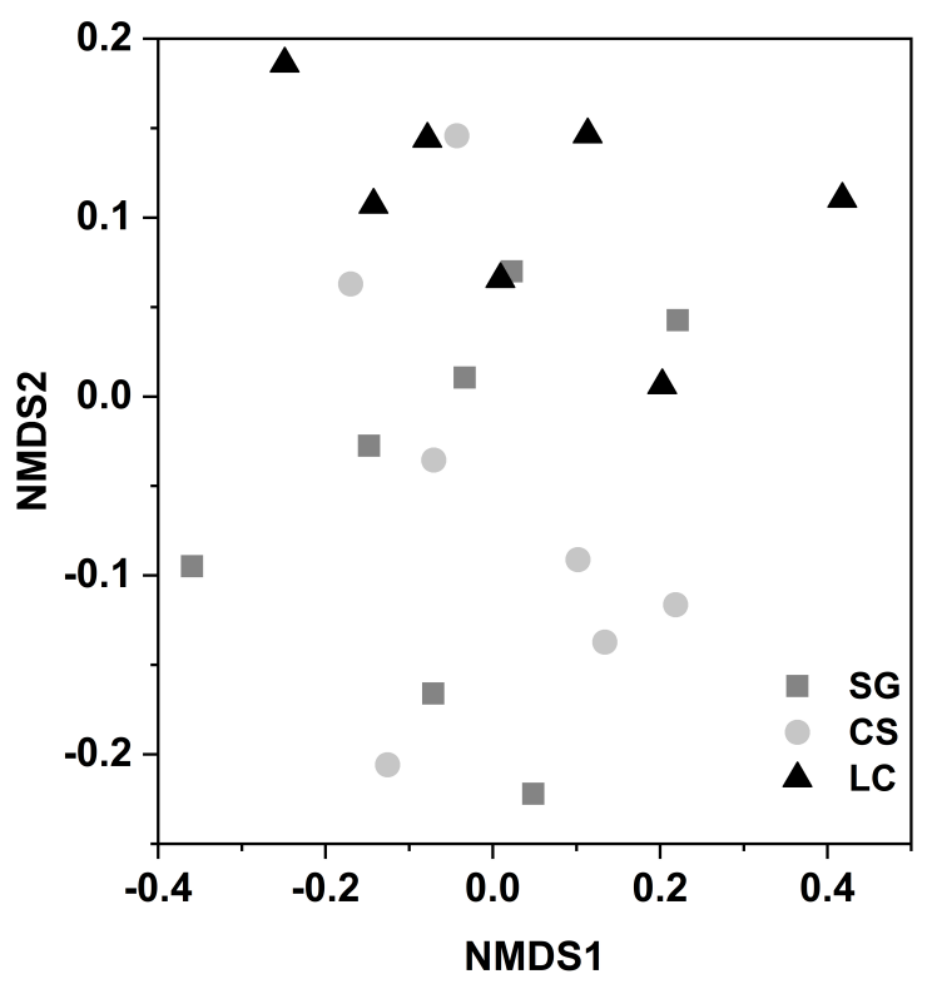

Figure 8. NMDS analysis. Non-metric multidimensional scaling (NMDS) of the community composition of arbuscular mycorrhizal fungi in the three plant species from seven different sites (stress $=0.189)$. Gray square boxes correspond to $S G(S$. grandis $)$, light gray circles to CS $(C$. squarrosa), and black triangles to LC (L. chinensis)

\section{Discussion}

\section{AMF colonization}

In this study, AM fungal colonization in different plant species was high (85\%) at the beginning of the growing season, which is in line with the distinct colonization rates studied previously among different co-occurring plants ( $\mathrm{Li}$ et al., 2010; Lugo et al., 2003; Su et al., 2011). However, the rate of colonization was non-significant among the threes species, which is consistent with $\mathrm{Su}$ et al. (2011). Studies on AM fungal colonization in Inner Mongolia, tallgrass prairie grasses and six locations on the European coast showed similar results in early growth seasons, and AMF colonization was the highest in this period (Bentivenga and Hetrick, 1992; Rodríguez-Echeverría et al., 2008; Su et al., 2011). This is because during the early growing season, the plants grow fast with high metabolic activity and high level of nutrient exchange between host plants and fungi, leading to a higher percentage of AM colonization (Baslam et al., 2011; Bentivenga and Hetrick, 1992; Muthukumar and Udaiyan, 2002; Wang et al., 2015; Su et al., 2011). The structures of AMF, including vesicles and arbuscules are essential sites for nutrient storage and their exchange between the host plants and fungi (Müller et al., 2017; Berruti et al., 2016). Moreover, genus Glomus was found to be the most abundant, suggesting that the AMF species belonging to this genus can produce more hyphal segments and spores that can colonize onto plant roots extensively (Zhao et al., 2017). Consistent with this, all three plant species, in our study, were dominated by Glomus showing the highest percentage of AMF colonization. 


\section{AM fungal diversity and community composition}

We found that the number of sequence types/OTUs detected were 51, inferring the rich AMF diversity in this typical steppe. The species richness of AMF in the roots of $S$. grandis, C. squarrosa, and L. chinensis was 32, 20, and 25, respectively. Moreover, the diversity indexes also indicated the high diversity in all three plant species, especially in $S$. grandis. These findings are supported by the previous studies showing that the plant species in the field conditions held higher AMF diversity in their roots (Öpik et al., 2006; Torrecillas et al., 2012), and perennial plant species of semiarid region hosted the higher AM fungal diversity in their roots (Alguacil et al., 2012). Moreover, the AM fungal community in the current research exhibited that $50 \%$ of the total OTUs were contributed from the genus Glomus, suggesting it as the most abundant and wide spread genus among the three plant species. These results supported the previous reports that widely distributed AMF had higher abundance in the local environment but with low host specificity (Husband et al., 2002; Öpik et al., 2006; Wirsel, 2004). Moreover, it is also documented that AMF diversity increases with the increase in plant diversity (Alguacil et al., 2011; Torrecillas et al., 2012) because different plant species dominate the typical steppe of Inner Mongolia during the growing season (Su et al., 2011). This explanation is in agreement with our results that $S$. grandis showed a greater extent of AM fungal diversity when compared to L. chinensis and C. squarrosa, as S. grandis also held the highest AMF colonization, which may be attributed to the colonization of more diversified AMF taxa. Alguacil et al. (2011) also concluded that the non-metric multidimensional scaling plot revealed that AM fungal communities of all three plants overlapped, suggesting low host specificity of AMF for these species. This might be because all the species belong to the same family poaceae. This is also in line with previous finding stating the absence of host specificity in poaceae (Torrecillas et al., 2012). Another explanation could be that the composition of host plant does not effectively influence AM fungal communities. There are also some environmental factors that have substantial effects on the community composition of AMF such as soil properties including structure (Lekberg et al., 2007), fertility (Egerton-Warburton et al., 2007; del Mar Alguacil et al., 2010), moisture content (Wolfe et al., 2007), disturbance (Rodríguez-Echeverría and Freitas, 2006), and climatic factors including temperature and precipitation (Treseder, 2013). Widespread study in Tibetan alpine steppe stated that different plants at the same site had no significant difference in AMF community composition in their rhizosphere soil (Zhang et al., 2016a). In most cases, the AMF community associated with the respective host is not so unique, and there is the probability that a subset of that AMF community is also connected with many other host plants, and it has been reported that a limited number of fungal species associated with globally $90 \%$ of plant families, resulting in lower host specificity of AMF (Natasha Teutsch and Hawkes, 2010). In contrast, there are also mounting evidences indicating that co-occurring plant species held apparently distinct AM fungal communities within their roots, including plants in tropical forests (Husband et al., 2002), permanent grasslands (Vandenkoornhuyse et al., 2003), oak-woodlands (Douhan et al., 2005), semiarid coastal dunes (Martínez-García and Pugnaire, 2011), high mountainous meadows (Sýkorová et al., 2007), and farmland (Paul et al., 2013).

Despite the overall community composition similarity, in terms of genus and OTUs, some AMF were still found to be specific to their host plants in our study (Table 1). Likely, Lugo and Cabello (2012) found that some AMF species were limited to $B$. subarista and P. stuckertii, whereas the Glomus species was only associated with $P$. 
stuckertii. Thus, the effects of host plant on AM fungal community composition are still controversial and needs further research to disentangle the reality.

\section{Conclusion}

In summary, the overall higher rate of mycorrhizal colonization in the roots of three dominant species of Xilinguole typical grassland reflects the strong association and mutual relationship of plant-AMF. Moreover, there were significant differences in species richness of AMF among the three perennial plant species. However, there were no significant differences in community composition of AMF; some genera exposed a little host preference, wherein Glomus was the most dominant in reflecting the actual community composition. These findings can be of vital importance in studying the success of plant species in their ecosystems based on the integrity of their symbiotic relationships with AMF.

Acknowledgements. The authors would like to appreciate Lin Zhang, Xin Lin, M. Zeeshan Munir, ZaibUn-Nisa, Sagheer Ahmad, M. Imran, Arshad Iqbal, M. Amir, and Xinling Dai for their valuable suggestions in improving the manuscript and their help in different bioinformatics tools. We would like to thank Qiang Dong, Xin Guo, Yaoyao Lu for the assistance with field sampling, and Chengdu Institute of Biology of the Chinese Academy of Sciences for the support on DNA sequencing and bioinformatics analysis. This work was funded by the Special Fund for Forest Scientific Research in the Public Welfare (201404204-05A), the National Key Research and Development Program of China (2016YFC0501802), and the National Natural Science Foundation of China (31770542, 31761123001-1).

\section{REFERENCES}

[1] Alguacil, M., Torres, M., Torrecillas, E., et al. (2011): Plant type differently promote the arbuscular mycorrhizal fungi biodiversity in the rhizosphere after revegetation of a degraded, semiarid land. - Soil Biology and Biochemistry 43: 167-173.

[2] Alguacil, M., Torrecillas, E., Roldán, A., et al. (2012): Perennial plant species from semiarid gypsum soils support higher AMF diversity in roots than the annual Bromus rubens. - Soil Biology and Biochemistry 49: 132-138.

[3] Baslam, M., Garmendia, I., Goicoechea, N. (2011): Arbuscular mycorrhizal fungi (AMF) improved growth and nutritional quality of greenhouse-grown lettuce. - Journal of Agricultural and Food Chemistry 59: 5504-5515.

[4] Bentivenga, S., Hetrick, B. (1992): Seasonal and temperature effects on mycorrhizal activity and dependence of cool-and warm-season tallgrass prairie grasses. - Canadian Journal of Botany 70: 1596-1602.

[5] Berruti, A., Lumini, E., Balestrini, R., et al. (2016): Arbuscular mycorrhizal fungi as natural biofertilizers: let's benefit from past successes. - Frontiers in Microbiology 6: 1559 .

[6] Bever, J. D. (2002): Host-specificity of AM fungal population growth rates can generate feedback on plant growth. - Plant and Soil 244: 281-290.

[7] Bonfante, P., Genre, A. (2010): Mechanisms underlying beneficial plant-fungus interactions in mycorrhizal symbiosis. - Nature Communications 1: 48.

[8] Chen, M., Yang, G., Sheng, Y., et al. (2017): Glomus mosseae inoculation improves the root system architecture, photosynthetic efficiency and flavonoids accumulation of Liquorice under nutrient stress. - Frontiers in Plant Science 8: 931.

[9] Clapp, J., Young, J., Merryweather, J., et al. (1995): Diversity of fungal symbionts in arbuscular mycorrhizas from a natural community. - New Phytologist 130: 259-265. 
[10] del Mar Alguacil, M., Lozano, Z., Campoy, M. J., et al. (2010): Phosphorus fertilisation management modifies the biodiversity of AM fungi in a tropical savanna forage system. Soil Biology and Biochemistry 42: 1114-1122.

[11] del Mar Alguacil, M., Díaz, G., Torres, M. P., et al. (2018): Host identity and functional traits determine the community composition of the arbuscular mycorrhizal fungi in facultative epiphytic plant species. - bioRxiv 307991.

[12] Desai, S., Kumar, G. P., Amalraj, L. D., et al. (2016): Exploiting PGPR and AMF Biodiversity for Plant Health Management. - In: Singh, D. P. et al. (eds.) Microbial Inoculants in Sustainable Agricultural Productivity. Springer, India, pp. 145-160.

[13] Douhan, G. W., Petersen, C., Bledsoe, C. S., et al. (2005): Contrasting root associated fungi of three common oak-woodland plant species based on molecular identification: host specificity or non-specific amplification? - Mycorrhiza 15: 365-372.

[14] Egerton-Warburton, L. M., Johnson, N. C., Allen, E. B. (2007): Mycorrhizal community dynamics following nitrogen fertilization: a cross-site test in five grasslands. - Ecological Monographs 77: 527-544.

[15] Eom, A.-H., Hartnett, D. C., Wilson, G. W. (2000): Host plant species effects on arbuscular mycorrhizal fungal communities in tallgrass prairie. - Oecologia 122: 435444.

[16] Harrier, L. (2001): The arbuscular mycorrhizal symbiosis: a molecular review of the fungal dimension. - Journal of Experimental Botany 52: 469-478.

[17] He, F., Wang, K., Hannaway, D. B., et al. (2017): Effects of precipitation and clipping intensity on net primary productivity and composition of a Leymus chinensis temperate grassland steppe. - PloS One 12: e0190450.

[18] Helgason, T., Daniell, T. J., Husband, R., et al. (1998): Ploughing up the wood-wide web? - Nature 394: 431.

[19] Helgason, T., Fitter, A. H., Young, J. P. W. (1999): Molecular diversity of arbuscular mycorrhizal fungi colonising Hyacinthoides non-scripta (bluebell) in a seminatural woodland. - Mol Ecol 8(4): 659-666.

[20] Helgason, T., Merryweather, J., Denison, J., et al. (2002): Selectivity and functional diversity in arbuscular mycorrhizas of co-occurring fungi and plants from a temperate deciduous woodland. - Journal of Ecology 90: 371-384.

[21] Huang, Y.-M., Zou Y-N and Wu Q-S. (2017): Alleviation of drought stress by mycorrhizas is related to increased root $\mathrm{H} 2 \mathrm{O} 2$ efflux in trifoliate orange. - Scientific Reports 7: 42335.

[22] Husband, R., Herre, E. A., Turner, S., et al. (2002): Molecular diversity of arbuscular mycorrhizal fungi and patterns of host association over time and space in a tropical forest. - Molecular Ecology 11: 2669-2678.

[23] Krüger, M., Stockinger, H., Krüger, C., et al. (2009): DNA-based species level detection of Glomeromycota: one PCR primer set for all arbuscular mycorrhizal fungi. - New Phytologist 183: 212-223.

[24] Krüger, M., Krüger, C., Walker, C., et al. (2012): Phylogenetic reference data for systematics and phylotaxonomy of arbuscular mycorrhizal fungi from phylum to species level. - New Phytologist 193: 970-984.

[25] Kumar, S., Tamura, K., Jakobsen, I. B., et al. (2007): MEGA4: Molecular Evolutionary Genetics Analysis (MEGA) software version 4.0. - Molecular Biology \& Evolution 24: 1596.

[26] Latef, A. A. H. A., Hashem, A., Rasool, S., et al. (2016): Arbuscular mycorrhizal symbiosis and abiotic stress in plants: A review. - Journal of plant biology 59: 407-426.

[27] Lee, E.-H., Eo, J.-K., Ka, K.-H., et al. (2013): Diversity of arbuscular mycorrhizal fungi and their roles in ecosystems. - Mycobiology 41: 121-125.

[28] Lekberg, Y., Koide, R. T., Rohr, J. R., et al. (2007): Role of niche restrictions and dispersal in the composition of arbuscular mycorrhizal fungal communities. - Journal of Ecology 95: 95-105. 
[29] Li, L.-F., Li, T., Zhang, Y., et al. (2010): Molecular diversity of arbuscular mycorrhizal fungi and their distribution patterns related to host-plants and habitats in a hot and arid ecosystem, southwest China. - FEMS Microbiology Ecology 71: 418-427.

[30] Li, X., Zhu, T., Peng, F., et al. (2015): Inner Mongolian steppe arbuscular mycorrhizal fungal communities respond more strongly to water availability than to nitrogen fertilization. - Environmental Microbiology 17: 3051-3068.

[31] Liang, C., Michalk, D., Millar, G. (2002): The ecology and growth patterns of Cleistogenes species in degraded grasslands of eastern Inner Mongolia, China. - Journal of Applied Ecology 39: 584-594.

[32] López-García, Á., Palenzuela, J., Barea, J. M., et al. (2014): Life-history strategies of arbuscular mycorrhizal fungi determine succession into roots of Rosmarinus officinalis L., a characteristic woody perennial plant species from Mediterranean ecosystems. Plant and Soil 379: 247-260.

[33] Lugo, M. A., Cabello, M. N. (2002): Native arbuscular mycorrhizal fungi (AMF) from mountain grassland (Córdoba, Argentina) I. Seasonal variation of fungal spore diversity. - Mycologia 94: 579-586.

[34] Lugo, M. A., González Maza, M. E., Cabello, M. N. (2003): Arbuscular mycorrhizal fungi in a mountain grassland II: Seasonal variation of colonization studied, along with its relation to grazing and metabolic host type. - Mycologia 95: 407-415.

[35] Martínez-García, L. B., Pugnaire, F. I. (2011): Arbuscular mycorrhizal fungi host preference and site effects in two plant species in a semiarid environment. - Applied Soil Ecology 48: 313-317.

[36] Mcgonigle, T. P., Miller, M. H., Evans, D. G., et al. (1990): A new method which gives an objective measure of colonization of roots by vesicular - arbuscular mycorrhizal fungi. - New Phytologist 115: 495-501.

[37] Müller, A., Ngwene, B., Peiter, E., et al. (2017): Quantity and distribution of arbuscular mycorrhizal fungal storage organs within dead roots. - Mycorrhiza 27: 201-210.

[38] Muthukumar, T., Udaiyan, K. (2002): Seasonality of vesicular-arbuscular mycorrhizae in sedges in a semi-arid tropical grassland. - Acta Oecologica 23: 337-347.

[39] Natasha Teutsch, H., Hawkes, C. V. (2010): Plant neighborhood control of arbuscular mycorrhizal community composition. - New Phytologist 183: 1188-1200.

[40] Oksanen, J., Kindt, R., Legendre, P., et al. (2007): The vegan package. - Community Ecology Package 10: 631-637.

[41] Öpik, M., Moora, M., Liira, J., et al. (2003): Divergent arbuscular mycorrhizal fungal communities colonize roots of Pulsatilla spp. in boreal Scots pine forest and grassland soils. - New Phytologist 160: 581-593.

[42] Öpik, M., Moora, M., Liira, J., et al. (2006): Composition of root-colonizing arbuscular mycorrhizal fungal communities in different ecosystems around the globe. - Journal of Ecology 94: 778-790.

[43] Paul, G., Andrew, M., Maude, P., et al. (2013): Contrasting arbuscular mycorrhizal communities colonizing different host plants show a similar response to a soil phosphorus concentration gradient. - New Phytologist 198: 546-556.

[44] Pivato, B., Mazurier, S., Lemanceau, P., et al. (2007): Medicago species affect the community composition of arbuscular mycorrhizal fungi associated with roots. - New Phytologist 176: 197-210.

[45] Redecker, D., Cooper, J. E., Rao, J. R. (2006): Molecular Ecology of Arbuscular Mycorrhizal Fungi: A Review of PCR-Based Techniques. - In: Rao, J. R., Cooper, J. E. (eds.) Molecular Approaches to Soil Rhizosphere \& Plant Microorganism Analysis. CABI, Wallingford, UK.

[46] Ren, H., Han, G., Lan, Z., et al. (2016): Grazing effects on herbage nutritive values depend on precipitation and growing season in Inner Mongolian grassland. - Journal of Plant Ecology 9: 712-723. 
[47] Rodríguez-Echeverría, S., Freitas, H. (2006): Diversity of AMF associated with Ammophila arenaria ssp. arundinacea in Portuguese sand dunes. - Mycorrhiza 16: 543552.

[48] Rodríguez-Echeverría, S., Hol, W. G., Freitas, H., et al. (2008): Arbuscular mycorrhizal fungi of Ammophila arenaria (L.) Link: spore abundance and root colonisation in six locations of the European coast. - European Journal of Soil Biology 44: 30-36.

[49] Santos, J. C., Finlay, R. D., Tehler, A. (2006): Molecular analysis of arbuscular mycorrhizal fungi colonising a semi-natural grassland along a fertilisation gradient. New Phytologist 172: 159-168.

[50] Schloss, P. D., Westcott, S. L., Ryabin, T., et al. (2009): Introducing mothur: opensource, platform-independent, community-supported software for describing and comparing microbial communities. - Applied \& Environmental Microbiology 75: 75377541.

[51] Shannon, C. E., Weaver, W. (1949): The Mathematical Theory of Communication. University of Illinois Press, Urbana, pp. 24-30.

[52] Simon, L., Lalonde, M., Bruns, T. D. (1992): Specific amplification of $18 \mathrm{~S}$ fungal ribosomal genes from vesicular-arbuscular endomycorrhizal fungi colonizing roots. Applied \& Environmental Microbiology 58: 291-295.

[53] Smith, S., Read, D. (2008): Mycorrhizal Symbiosis. 3rd Ed. - Academic-Elsevier, London.

[54] Stürmer, S. L. (2012): A history of the taxonomy and systematics of arbuscular mycorrhizal fungi belonging to the phylum Glomeromycota. - Mycorrhiza 22: 247-258.

[55] Su, Y.-Y., Guo L.-D., Hyde, K. D. (2010): Response of endophytic fungi of Stipa grandis to experimental plant function group removal in Inner Mongolia steppe, China. - Fungal Diversity 43: 93-101.

[56] Su, Y.-Y., Sun, X., Guo L-D. (2011): Seasonality and host preference of arbuscular mycorrhizal fungi of five plant species in the Inner Mongolia steppe, China. - Brazilian Journal of Microbiology 42: 57-65.

[57] Sýkorová, Z., Wiemken, A., Redecker, D. (2007): Cooccurring Gentiana verna and Gentiana acaulis and their neighboring plants in two Swiss upper montane meadows harbor distinct arbuscular mycorrhizal fungal communities. - Applied and Environmental Microbiology 73: 5426-5434.

[58] Tamura, K., Dudley, J., Nei, M., et al. (2007): MEGA4: Molecular Evolutionary Genetics Analysis (MEGA) software version 4.0. - Molecular Biology \& Evolution 24: 15961599.

[59] Team R Core (2013): R: A Language and Environment for Statistical Computing. - R Core Team, Vienna.

[60] Torrecillas, E., Alguacil, M., Roldán, A. (2012): Host preferences of AM fungi colonizing annual herbaceous plant species in semiarid Mediterranean prairies. - Applied and Environmental Microbiology AEM. 01287-01212.

[61] Treseder, K. K. (2013): The extent of mycorrhizal colonization of roots and its influence on plant growth and phosphorus content. - Plant and Soil 371: 1-13.

[62] Vandenkoornhuyse Á., Ridgway, K., Watson, I., et al. (2003): Co-existing grass species have distinctive arbuscular mycorrhizal communities. - Molecular Ecology 12: 30853095.

[63] Wang, Y., Li, T., Li, Y., et al. (2015): Community dynamics of arbuscular mycorrhizal fungi in high-input and intensively irrigated rice cultivation systems. - Applied and Environmental Microbiology AEM. 03769-03714.

[64] White, T. J., Bruns, T., Lee, S., et al. (1990): Amplification and Direct Sequencing of Fungal Ribosomal RNA Genes for Phylogenetics. - In: Innis, M. A. et al. (eds.) PCR Protocols. A Guide to Methods and Applications. Academic Press, New York, pp. 315322 
[65] Wirsel, S. G. (2004): Homogenous stands of a wetland grass harbour diverse consortia of arbuscular mycorrhizal fungi. - FEMS Microbiology Ecology 48: 129-138.

[66] Wolfe, B. E., Mummey, D. L., Rillig, M. C., et al. (2007): Small-scale spatial heterogeneity of arbuscular mycorrhizal fungal abundance and community composition in a wetland plant community. - Mycorrhiza 17: 175-183.

[67] $\mathrm{Xu}, \mathrm{H} ., \mathrm{Su}, \mathrm{H} ., \mathrm{Su}, \mathrm{B}$., et al. (2014): Restoring the degraded grassland and improving sustainability of grassland ecosystem through chicken farming: a case study in northern China. - Agriculture, Ecosystems \& Environment 186: 115-123.

[68] Zhang, J., Wang, F., Che, R., et al. (2016a): Precipitation shapes communities of arbuscular mycorrhizal fungi in Tibetan alpine steppe. - Scientific Reports 6: 23488.

[69] Zhang, L., Xu, M., Liu, Y., et al. (2016b): Carbon and phosphorus exchange may enable cooperation between an arbuscular mycorrhizal fungus and a phosphate-solubilizing bacterium. - New Phytologist 210: 1022-1032.

[70] Zhang, Q., Yang, R., Tang, J., et al. (2010): Positive feedback between mycorrhizal fungi and plants influences plant invasion success and resistance to invasion. - PloS One 5: e12380.

[71] Zhao, H., Li, X., Zhang, Z., et al. (2017): Species diversity and drivers of arbuscular mycorrhizal fungal communities in a semi-arid mountain in China. - Peerj 5: e4155.

[72] Zheng, Y., Chen, L., Luo, C.-Y., et al. (2016): Plant identity exerts stronger effect than fertilization on soil arbuscular mycorrhizal fungi in a sown pasture. - Microbial Ecology 72: 647-658. 